\title{
Optimized Harmonic Reduction PWM based Control Technique for Three-Phase Quasi Z-Source Inverter
}

\author{
Pritam Kumar Gayen ${ }^{1 *}$, Archak Sadhukhan ${ }^{2}$ \\ 1,2 Kalyani Government Engineering College, India \\ Email: ${ }^{1}$ pritamgayen@rediffmail.com, ${ }^{2}$ archksdkn@gmail.com \\ *Corresponding Author
}

\begin{abstract}
This paper proposes an optimized harmonic reduction pulse width modulation (HRPWM) control strategy for three-phase quasi Z-source inverter (qZSI). In traditional sinusoidal or space vector pulse width modulation techniques, the flexibility in adjustment of individual switching angles is not possible and thus, these techniques are not optimum choices for low switching frequency operations of high/medium power qZSI. In the proposed technique, adjustments of switching angles of HRPWM waveform are possible to achieve optimum performance. The optimum performance is targeted as maximization of boosting factor and simultaneous minimization of weighted total harmonic distortion (WTHD) at the output voltage of qZSI. The hybrid particle swarm optimization gravitational search algorithm (PSOGSA) is used for computation of optimum switching angles of suggested HRPWM waveform at various modulation indices. The obtained WTHDs up to 49th order harmonics and boosting factors of optimized HRPWM methodology are compared with that of the maximum boost control (MBC) technique for qZSI to justify superior performances of the suggested method in low switching frequency range. The proposed concept has been verified via simulation study. The experimentation (qZSI controlled by microcontroller) validates the working of optimized HRPWM based qZSI which agrees with software results.
\end{abstract}

Keywords - quasi Z-souce inverter, Harmonic reduction pulse width modulation, Weighted total harmonic distortion, Voltage boost, PSOGSA optimization technique.

\section{INTRODUCTION}

In recent years, Z-source inverter (ZSI) / quasi Z-source inverter (qZSI) [1] based solar and fuel energy conversion systems [2-5] are getting importance for generation of electrical energy. Due to their growth in electrical power generation scenario, ZSI/qZSI is applied to grid level conversion process [6]. The ZSI/qZSI is single stage inverter topology having voltage boost capability. The circuit diagram of qZSI topology [7, 8] (improved version of ZSI) is shown in Fig. 1 which constitutes an impedance network in front of inverter bridge. The input side impedance network ( $\mathrm{Z}$ network) comprises of two capacitors $\left(\mathrm{C}_{1}, \mathrm{C}_{2}\right)$, two inductors $\left(\mathrm{L}_{1}, \mathrm{~L}_{2}\right)$ and a diode (D) for boosting up the DC bus voltage for the inverter bridge.

The different control schemes [9] are developed as outcome of continuous research works in progress of time. In the context of control mechanism, type of pulse width modulation (PWM) technique decides the performance of
qZSI. Various kinds of sine PWM (SPWM) or space vector PWM (SVPWM) method are proposed in published papers [3, 10-23]. Each kind of PWM method involves shootthrough duty ratio control to facilitate DC side voltage boosting process and also, simultaneous control of modulation index for obtaining expected voltage gain for qZSI. In earlier stage, the various SPWM techniques for qZSI are proposed as simple boost control (SBC) [3], maximum boost control (MBC) [11] and maximum constant boost control (MCBC) [14] PWMs. One unified control technique using space vector concept is presented in [16]. The comparative performance of theoretical and experimental evaluation of four no SVPWM techniques for qZSI are elaborately presented in the paper [17]. In very recent years, various improvements over traditional PWM methods, namely extended maximum boost control [21], improved PWM with maximum boost capability cum minimum switching frequency [22] and time-variant shoot-through (TVST) modulation [23] have been proposed. The harmonics productions in qZSI and comparative assessments are elaborately presented in articles [24, 25].

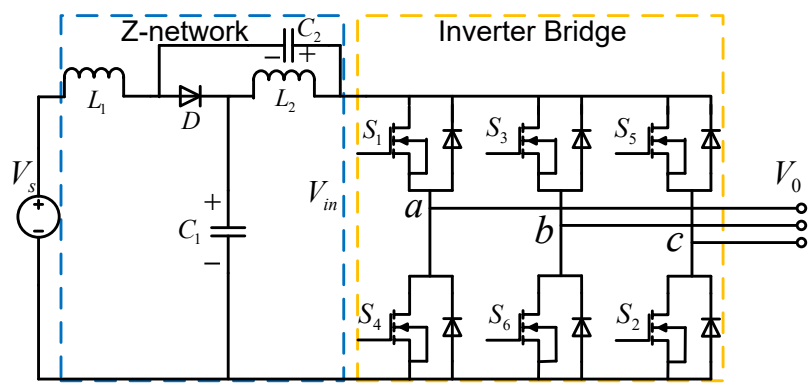

Fig. 1. Circuit diagram of qZSI.

Various PWM schemes cited above are of high switching frequency. For medium or high power qZSI, comparatively lower switching frequency PWM scheme is desirable. But, low switching frequency PWM normally produces more harmonics which are required to be reduced by appropriate mechanism in PWM technique for avoiding/lowering filtering requirement. In addition to this, voltage boosting action is simultaneously necessary for the operation of qZSI. Therefore, the research work of this paper proposes an optimized harmonic reduction PWM (HRPWM) technique $[26,27]$ for qZSI in low switching frequency range. Here, the joint objectives are taken as minimization of weighted total 
harmonic distortion (WTHD) and simultaneously maximization of boosting capability at various values of modulation index. In the logic, optimum switching angles of HRPWM signal are calculated using hybrid particle swarm optimization gravitational search algorithm (PSOGSA) [28] to meet the dual requirements. The MATLAB-SIMULINK $2014 \mathrm{~b}$ software is used to validate the proposed methodology. Then, experimental work is also done in laboratory to justify the suggested concept. The values of WTHD up to $49^{\text {th }}$ order and boosting factor at various modulation indices are compared with that of the MBC technique to prove the superiority of optimized HRPWM scheme in low switching frequency range.

The equations for describing the operations of qZSI are provided in section II. Section III discusses the proposed HRPWM methodology and allied analysis. Section IV presents both simulation and experimental studies to justify the superiority of suggested modulation concept. Finally, the core findings of the work are concluded in section $\mathrm{V}$.

\section{BASICS OF QZSI}

The various equations for describing the operation of qZSI are presented in section 2. The qZSI has two operating states, namely shoot-through and non shoot-through states. The non-shoot through state covers both active and zero states. The shoot-through time span decides the amount of boosted voltage, whereas the non shoot-through state determines the output voltage of the inverter. Thus, any PWM logic for qZSI must incorporate shoot-through, active and/or zero states for the desirable operation of qZSI. Depending upon the type of PWM logic, the time duration of active state, zero state and shoot-through state varies. Hence, the performance of qZSI operated by any PWM logic is different from that of the other PWMs. The fundamental equations under two modes of operation can be summarized as follows:

The amplitude of input side boosted DC voltage during shoot-through time span is given by,

$$
\begin{gathered}
\hat{V}_{i n}=\frac{1}{1-2 D_{s h}} V_{s} \\
B=\frac{1}{1-2 D_{s h}}
\end{gathered}
$$

Where $D_{s h}=$ shoot-through duty ratio, $B=$ boosting factor. The peak value of fundamental component of output voltage is guided by the value of modulation index $(M)$ and it can be expressed as,

$$
\hat{V}_{0}=M B V_{s} / 2
$$

Thus, the overall voltage gain ( $G$ ) is defined from (3) as,

$$
G=M B=\frac{1}{1-2 D_{s h}} M
$$

\section{PROPOSED OPTIMISED HRPWM METHODOLOGY}

The fundamental idea of the proposed PWM method is the realization of combined objective as minimization of WTHD cum boosting factor maximization logic at each modulation index. This PWM pattern has comparatively lower switching transitions per cycle, thus it can be stated as efficient logic for high power converter. Both the objectives are targeted by the usage of optimization based approach to determine the switching angles (output variables for the mathematical problem). At first, the expressions of WTHD in terms of the switching angles are given. Then, the logic of incorporation of shoot-through span in the proposed PWM waveform and the determination of boosting factor are presented. Finally, PSOGSA based approach for achieving the aforementioned combined objective is presented as follows:

\section{A. Expression of WTHD}

The output pole voltage waveform of without incorporating shoot-through time span is shown in Fig. 2 which has ' $m$, numbers of switching angles per quarter cycle waveform.

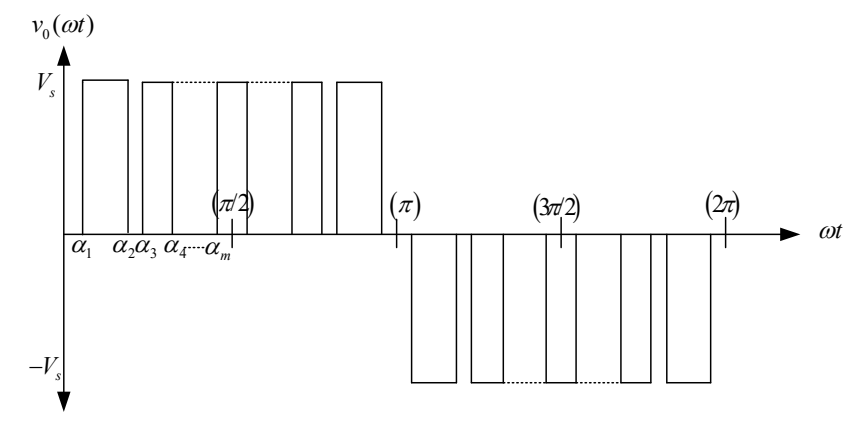

Fig. 2. Voltage waveform.

In general, the periodic waveform shown in Fig. 2 can be expressed in trigonometric form of Fourier series as,

$$
v_{0}(\omega t)=\sum_{n=1}^{\infty}\left(a_{n} \cos n \omega t+b_{n} \sin n \omega t\right)
$$

The ' $n$ ' indicates harmonic order in (5). In (5), the coefficient ' $a_{n}$ ' equals to zero due to odd symmetry of the waveform. The other coefficient ' $b_{n}$ ' for the half-wave symmetry waveform can be calculated $[29,30]$ as,

$$
\left\{\begin{array}{l}
b_{1}=-\left(\frac{4}{\pi}\right)\left[\sum_{k=1}^{m}(-1)^{k} \cos \alpha_{k}\right] \\
b_{n}=-\left(\frac{4}{n \pi}\right)\left[\sum_{k=1}^{m}(-1)^{k} \cos n \alpha_{k}\right] ; n \neq 1, \text { even }
\end{array}\right.
$$

The coefficients in (6) are expressed in per unit (p.u.) value. It is evident from (6) that the fundamental and harmonic components are dependent on the switching angles. For keeping harmonics values within tolerance level at a particular modulation index, (7) is formed as,

$$
\left\{\begin{array}{l}
b_{1}=M \\
b_{n} \leq \varepsilon_{n} ; n \neq 1, \text { even, triplen }
\end{array}\right.
$$

Triplen harmonics are omitted in (7) due to their absence in line-line voltage of three phase system under balanced condition. In this context, WTHD can be mathematically represented as,

$$
W T H D=\left[\frac{1}{b_{1}^{2}} \sum_{n=5}^{\infty}\left(b_{n} / n\right)^{2}\right]^{1 / 2} ; n=6 i \pm 1 ; i: 0 \rightarrow \infty(
$$

Thus, WTHD indirectly depends on the value of switching angles via Fourier coefficients ' $b_{n}$ ' using (8).

\section{B. Identification and Incorporation of ST}

It is expected that the shoot-through (ST) time span is inserted in the zero state of the proposed PWM signals for 
attaining boosting action. The typical quarter cycle symmetrical PWM waveforms for power semiconductor switches of qZSI are shown in Fig. 3(a) which can be used for identifying the zero states of the PWM logic. When the PWM waveforms for upper three switches $\left(\mathrm{S}_{1}, \mathrm{~S}_{3}, \mathrm{~S}_{5}\right)$ have simultaneous high or low states ('111' or ' 000 ' logic), the time span is considered as zero state of the PWM logic. It is evident from Fig. 3(a) that switching angles decide the amount of zero state time span i.e. the all one or all zero conditions of the upper switches in the PWM signals. The logical diagram for deciding the zero state as shown in Fig. 3(a) is presented in Fig. 3(b). Here, shoot-through state can be incorporated in PWM waveforms by covering whole zero states for maximization of boosting capability. The mean value of the cumulative shoot-through time span over the $1 / 6^{\text {th }}$ of fundamental period can be computed from shoot through waveform to get the value of shoot-through duty ratio. Then, the boosting factor is calculated using (2) as shown in Fig. 3 (c).

\section{Determination of Boosting Factor}

Here, it is also necessary to measure the shoot-through duty ratio to quantify the obtained boosting factor. Therefore, at first, the various shoot-through time spans or pattern over a fundamental period are determined following logic shown in Fig. 3(b). Then, the mean of the total shoot-through time span over $1 / 6^{\text {th }}$ of fundamental period are computed to get the value of shoot-through duty ratio. Finally, boosting factor is determined from the obtained shoot-through duty ratio using (2). These steps are shown in Fig. 3(c).

It can be commented from various discussions mentioned before under this section that the optimized choice of set of switching angles is necessary to maintain the balance between WTHD and boosting factor. In the context, hybrid particle swarm optimization gravitational search algorithm (PSOGSA) based approach is discussed in the next subsection.

\section{PSOGSA Approach}

From the above discussions, it can be stated here that the choice of switching angles plays crucial role for attaining minimum WTHD cum maximum boosting capability for each value of modulation index. Therefore, objective function $(J)$ combining the above targets are formed which is mathematically expressed in (9). The minimization of the objective function is considered in the study as reciprocal of boosting factor is taken in (9).

$$
J(\alpha)=\left[\frac{1}{b_{1}^{2}} \sum_{n=5}^{\infty}\left(b_{n} / n\right)^{2}\right]^{1 / 2} \cdot K_{1}+(1 / B) \cdot K_{2}
$$

In (9), the selection of weightage factors ' $k_{1}$ ' and ' $k_{2}$ ' decides accuracy of solution by maintaining balance between the two parts during minimization process. The corresponding constraints is written as,

$$
\left\{\begin{array}{l}
b_{1}=M \\
0<\alpha_{1}<\alpha_{2} \ldots \ldots \ldots<\alpha_{m}<\pi / 2 \\
D_{s h, \text { min }}<D_{s h}<D_{s h, \text { max }}
\end{array}\right.
$$

In (10), the additional constraint for shoot-through duty ratio is included in comparison to (7). For the constraint of duty ratio in (10), the upper and lower limits of shoot-through duty ratio (symbolized as $D_{s h, \text { min }}$ and $D_{s h \text {, max }}$ respectively) are included depending on the boosting range required in any specific application. In our case study, the limit of shootthrough duty ratio ranges between 0.1 and 0.5 . The mathematical problem formed in (9) and (10) need the usage of optimization technique for determining switching angles to satisfy the both targets. In this paper, hybrid particle swarm optimization gravitational search algorithm (PSOGSA) technique is adopted for obtaining optimum values of switching angles. Here, the various steps for computation of switching angles by minimizing the objective function expressed in (9) using PSOGSA technique is presented in Fig. 4.

It can be summarized that the following steps are needed for production of optimized HRPWM waveforms:

1. ' $m$ ' numbers of switching angles per quarter cycle are to be decided as designer's choice.

2. Optimum values of these switching angles are to be determined through simultaneous minimization of WTHD and maximization of BF using optimization algorithm.

3. Generation of three-phase PWM waveforms having quarter cycle symmetry using obtained optimum ' $m$ ' numbers of switching angles in step 2.

4. Production of ST pattern from quarter cycle symmetry PWM waveforms for upper three switches of qZSI.

5. Finally, HRPWM signals are generated via incorporation of obtained ST pattern into quarter cycle symmetry PWM waveforms for qZSI.

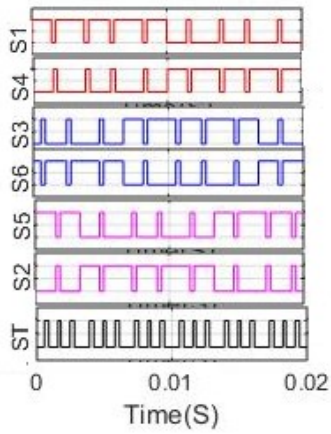

(a) Production of ST from PWM signals

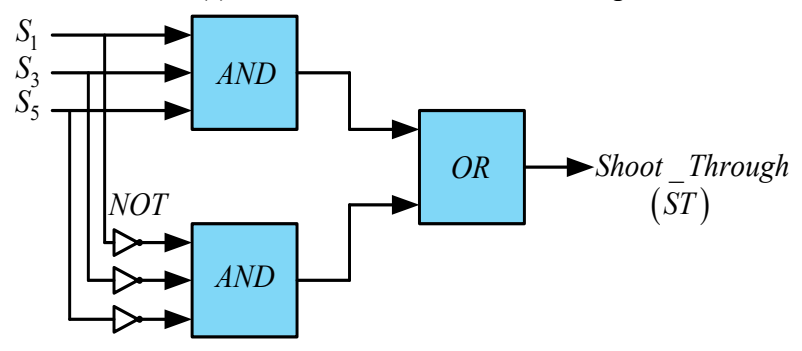

(b) ST production logic

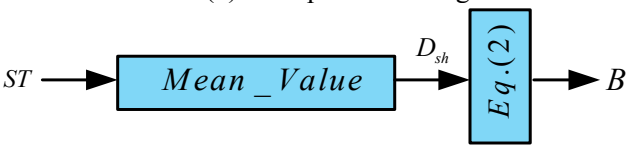

(c) Measurement of BF from ST pattern

Fig. 3. Identification and measurement of ST. 
p-1: Declaration of the maximum number of iteration (T) as $\mathbf{T}_{\max }$, Number of Particles $\mathbf{N}$, Number of variables $\mathbf{V}$, upper and lower limits of variables $\mathbf{V}_{\text {up }}=\mathbf{9 0}$ and $\mathbf{V}_{\text {low }}=\mathbf{0}$ and PSOGSA parameters $\mathbf{C}_{1}, \mathbf{C}_{2}$.

p-2: Initialisation of position randomly for each particle having value lies between $\mathbf{V}_{\text {up }}$ and $\mathbf{V}_{\text {low }}$ i.e. formation of position vector symbolized as ' $\boldsymbol{\alpha}_{\mathbf{N} \times \mathbf{V}}$ ', random initialisation of velocity for each position whose value is taken within 0.3 i.e. formation of velocity vector ' $\boldsymbol{\beta}_{\mathbf{N} \times \mathbf{V}}$ '; and initialization of force vector ' $\mathbf{F}_{\mathbf{N} \times \mathbf{V}}$ ' as zero vector.

p-3: Initialisation of particle best as Pbest $_{\mathbf{N} \times \mathbf{V}}=\boldsymbol{\alpha}_{\mathbf{N} \times \mathbf{V}}$. and PbestCost $_{\mathrm{N}}=$ infinity.

p-4: Starting of iteration i.e. $\mathbf{T}=\mathbf{0}$.

p-5: Calculation of gravitational constant $G=e^{\left(-23^{*} T / T m a x\right)}$

p-6: Calculation of fitness 'Fit ${ }_{\mathrm{N}}$ ' for every particle, from th objective function.

The objective function is $=\boldsymbol{k}_{\mathbf{1}} \times \boldsymbol{W T H} \boldsymbol{T}+\boldsymbol{k}_{\mathbf{2}} \times \frac{\mathbf{1}}{\boldsymbol{B}}$ subject to

$\left\{\begin{array}{c}b_{1}=M \\ 0<\alpha_{1}<\alpha_{2} \ldots<\alpha_{V}<\frac{\pi}{2} \\ D_{s h, \text { min }}<D_{\text {sh }}<D_{\text {sh,max }}\end{array}\right.$

p-7: Checking for each particle: if Fit $_{\mathbf{N}}<$ PbestCost $_{\mathbf{N}}$ then update both Pbest $_{\mathbf{N} \times \mathbf{V}}$ and PbestCost $\mathbf{P}_{\mathbf{N}}$

p-8: For the minimum value of PbestCost Pbe $_{\mathrm{N}}$, the corresponding position is stored at Gbest.

p-9: Saving the maximum and minimum value of Fit $\mathbf{v}_{\mathbf{v}}$ as Worse and Best.

p-10: Calculation of mass Mass $_{\mathbf{N}}=\left(\right.$ Fit $_{\mathbf{N}}-\mathbf{0 . 9 9}$ Worse $) /($ Best-Worse $)$ for each particle and also computation of total mass, Smass $=\mathbf{\Sigma}$ Mass $\mathbf{N}$.

p-11: Calculation of force on $i^{\text {th }}$ particle due to other particles.

$\mathrm{F}_{\mathrm{i} \times \mathrm{V}}=\mathrm{F}_{\mathrm{i} \times \mathrm{V}}+\sum_{j=1, j \neq i}^{N}$ rand $\times \frac{\operatorname{Mass}_{i} \times\left(\alpha_{j \times V}-\alpha_{i \times V}\right)}{\operatorname{Smass} \times\left|\alpha_{j \times V}-\alpha_{i \times V}\right|}$.

Where rand $=$ any random number between 0 and 1 ; ' $\mathrm{i}$ ' $\rightarrow 1$ to $\mathrm{N}$.

p-12: Calculation of acceleration vector

$\boldsymbol{A c c}_{\mathbf{N} \times \mathbf{V}}=\mathbf{S m a s s} \times \mathbf{F}_{\mathbf{N} \times \mathbf{V}} /\left(\mathbf{5} \times\right.$ Mass $\left._{\mathbf{N}}\right)$ and velocity vector $\beta_{\mathrm{N} \times \mathrm{V}}=\mathbf{r} * \beta_{\mathrm{N} \times \mathrm{V}}+\mathrm{C}_{1} * \mathbf{r} * \operatorname{Acc}_{\mathrm{N} \times \mathrm{V}}+\mathrm{C}_{2} * \mathbf{r} *\left(\right.$ Gbest $\left._{\mathrm{V}}-\boldsymbol{\alpha}_{\mathrm{N} \times \mathrm{V}}\right)$. where $\mathbf{r}=$ any random number between 0 and 1 ;

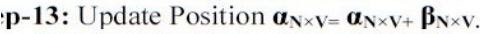

p-14: Limit Position values within $V_{\text {up }}$ and $V_{\text {low }}$

p-15: Update iteration $\mathbf{T}=\mathbf{T}+\mathbf{1}$ and

if $\mathbf{T}=\mathbf{T} \mathbf{m a x}$, then return the value $\mathbf{G b e s t}$ and corresponding fitness value as solution i.e. output else repeat from Step-5.

Fig. 4. Steps for computation of switching angle.

\section{RESULTS}

Both simulation study and experimental works are performed to validate the proposed optimization based PWM for the operation of qZSI. The passive parameters of qZSI used in these studies are given in Table I. The obtained results are presented as follows:

TABLE I. Values of Various Parameters

\begin{tabular}{|c|c|}
\hline TABLE I. Values of Various Parameters \\
\hline $\mathrm{L}_{1}, \mathrm{~L}_{2}$ & $4 \mathrm{mH}$ \\
$\mathrm{C}_{1}, \mathrm{C}_{2}$ & $470 \mu \mathrm{F}$ \\
\hline
\end{tabular}

\section{A. Simulation Study}

The programming for the calculation of switching angles using PSOGSA algorithm is written using MATLAB software. In the study, four switching angles per quarter wave are taken. The plot of obtained switching angles at various values of modulation index is presented in Fig. 5(a). The plot of WTHD versus modulation index is shown in Fig. 5(b). Here, WTHDs are computed up to 49th order harmonics. The corresponding values of boosting factors are plotted against modulation indices and the plot is presented in Fig. 5(c). The curve showing the convergence of WTHD and boosting factor at a particular modulation index of 0.8 per unit (p.u.) is given in Fig. 6 and the values are $4.3 \%$ and 3.48 respectively. It takes few iteration steps to converge.

Next, the performance of the proposed method is compared with that of the MBC scheme in Table 2 for various values of modulation index using SIMULINK software. The Table II indicates that superior performance in respect of BF and WTHD values are achieved in proposed case in comparison to $\mathrm{MBC}$ case at low switching frequency (450 $\mathrm{Hz}$ ) operation.

Here, the generation of HRPWM signal is realized and applied to the switches of qZSI in SIMULINK platform. The input DC voltage is taken as $150 \mathrm{~V}$. The PWM waveforms and allied shoot-through states at modulation index (M) of 0.8 p.u. (particular case study) are shown in Fig. 7. The plots of output phase voltage, current and FFT at the modulation index using SIMULINK software are given in Fig. 8. The phase voltage waveform is plotted in Fig. 8(a). The current waveform and its FFT spectrums are also shown in Fig. 8(b). The corresponding plot of boost-up DC bus voltage, voltages of impedance network capacitors are presented in Fig. 8(c) and $8(\mathrm{~d})$ respectively. Thus, the proposed concept is implemented in the simulation platform. In the next subsection, the hardware work is performed to validate the HRPWM concept.

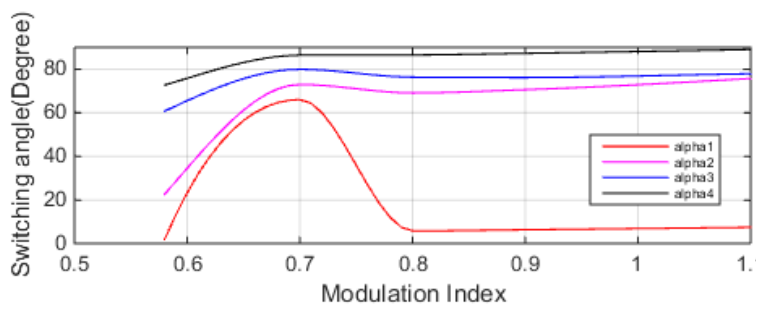

(a)

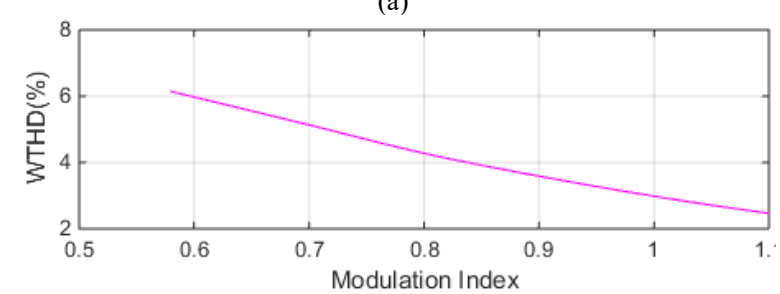

(b)


(c)

Fig. 5. (a) switching angles vs. modulation index (M), (b) WTHD vs. $\mathrm{M}$ and (c) B vs. M for overall M (upper) and zoomed plot for $\mathrm{M}=$ around 0.7 to 1 (lower). 


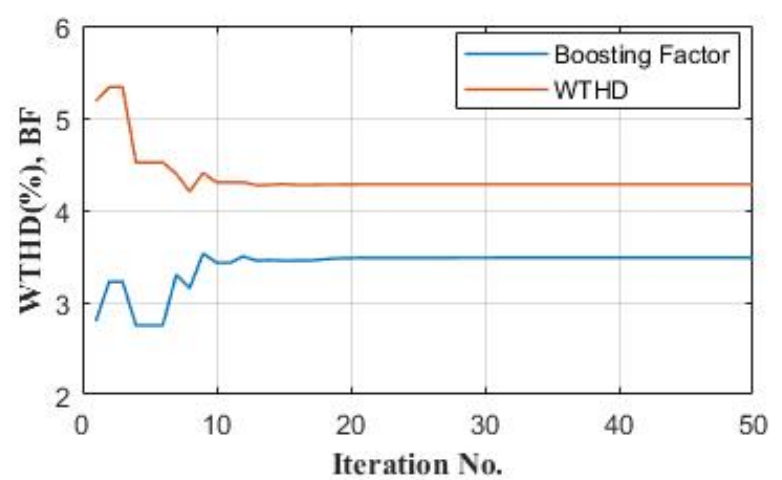

Fig. 6. Convergence of WTHD and B vs. iteration at M=0.8 p.u.

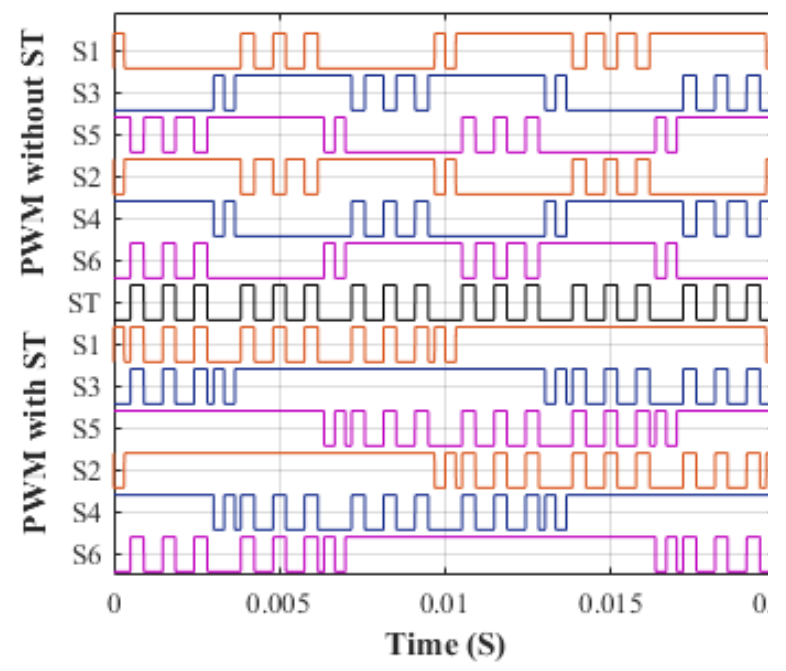

Fig. 7. PWM waveforms before and after incorporating shootthrough state and shoot-through pattern at $\mathrm{M}=0.8$.

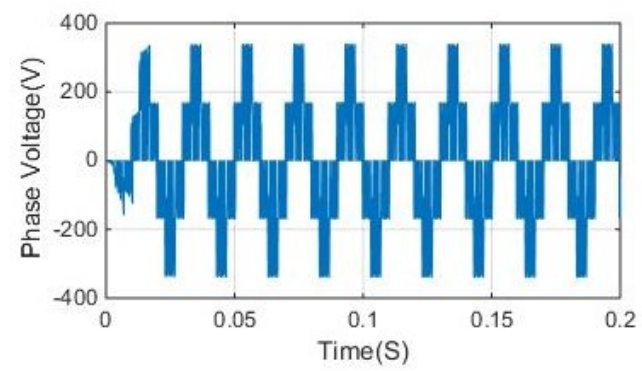

(a) Output phase voltage

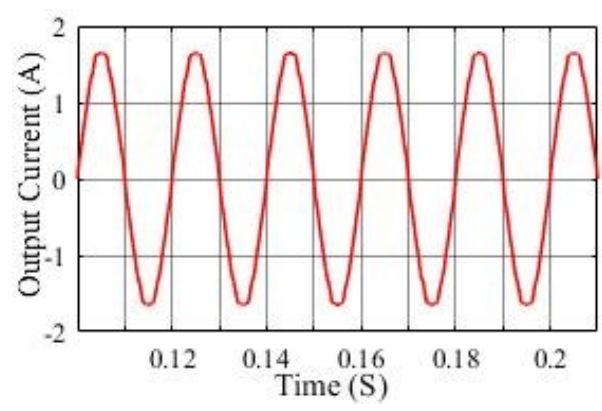

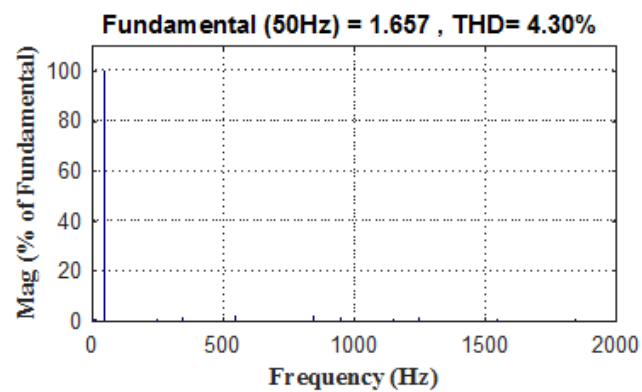

(b) Output phase current and FFT spectrum
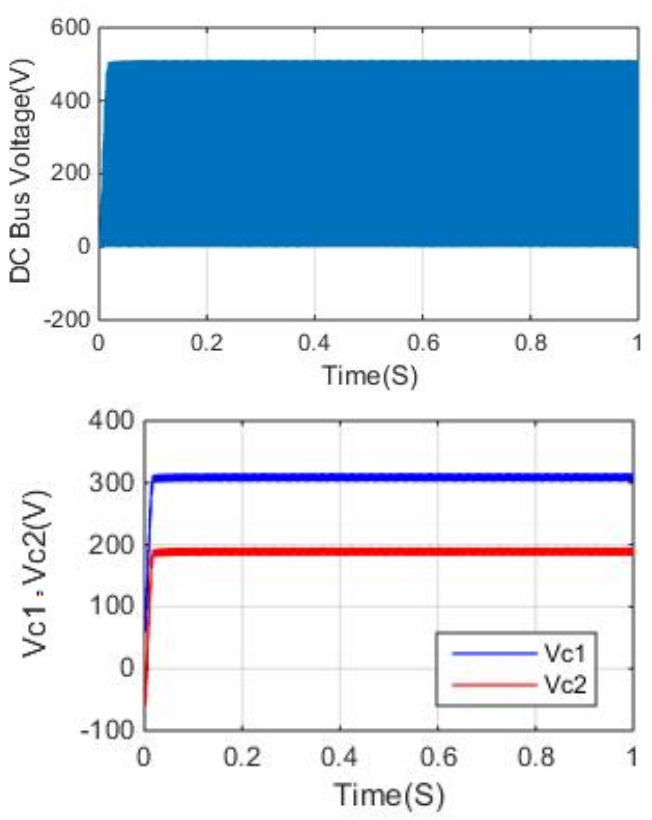

(c) DC link and capacitors voltages

Fig. 8. Various responses in SIMULINK platform at $\mathrm{M}=0.8 \mathrm{pu}$.

\begin{tabular}{|cccc|}
\multicolumn{4}{c}{ TABLE II. WTHD and BF Values at Different 'M' } \\
$\begin{array}{c}\text { Partic- } \\
\text { ulars }\end{array}$ & & & \\
& & & \\
& & WTHD & BF \\
& $(\mathrm{pu})$ & $(\mathrm{pu})$ & \\
& & & \\
PWM & & & 5.72 \\
& 0.7 & 6.1 & 2.9 \\
MBC & 0.8 & 5.8 & 1.94 \\
& 0.9 & 5.7 & 1.46 \\
\hline & 1 & 5.6 & 8.12 \\
HRPWM & 0.7 & 5 & 3.48 \\
& 0.8 & 4.3 & 2.2 \\
& 0.9 & 3.5 & 1.6 \\
\hline
\end{tabular}

\section{B. Experimental Study}

The laboratory prototype is designed to implement optimized HRPWM for operation of IGBT (CT60AM-18F) based three phase qZSI. The load box having switched resistors and inductors are used for electrical loading purpose. No additional output filter is used. The overall experimental set up is presented in Fig. 9. The obtained optimized switching angles using MATLAB software are stored in the memory of microcontroller (PIC18F67K22) as look-up table. The HRPWM signals for six switches are produced using the 
microcontroller from stored values of switching angles. The gate drive PWM signals at modulation index of 0.8 p.u. are shown in Fig. 10 (a), which is applied to the qZSI. The corresponding responses of DC bus voltage, capacitors voltages at the operating condition are shown in Fig. 10 (b). The plots of output voltage, output current and FFT spectrum of current are given in Fig. 10 (c) and (d) respectively. The 4channel, $200 \mathrm{MHz}$ digital storage oscilloscope (KEYSIGHT: DSOX2024A) is used to capture the various signals in hardware platform. The overall experimental work justifies the operation of qZSI with the proposed PWM technique.

From the studies, it can be stated the various significant benefits of the proposed PWM method are as follows:

1. It can maintain optimum level of harmonics at its output as per standard [31] at low switching frequency range.

2. Higher boosting of voltage is noticed in comparison with $\mathrm{MBC}$ technique at a particular ' $\mathrm{M}$ '.

3. Negotiation between WTHD and BF is possible using the proposed PWM logic.

Thus, the various notable features make this PWM scheme effective for high power qZSI.

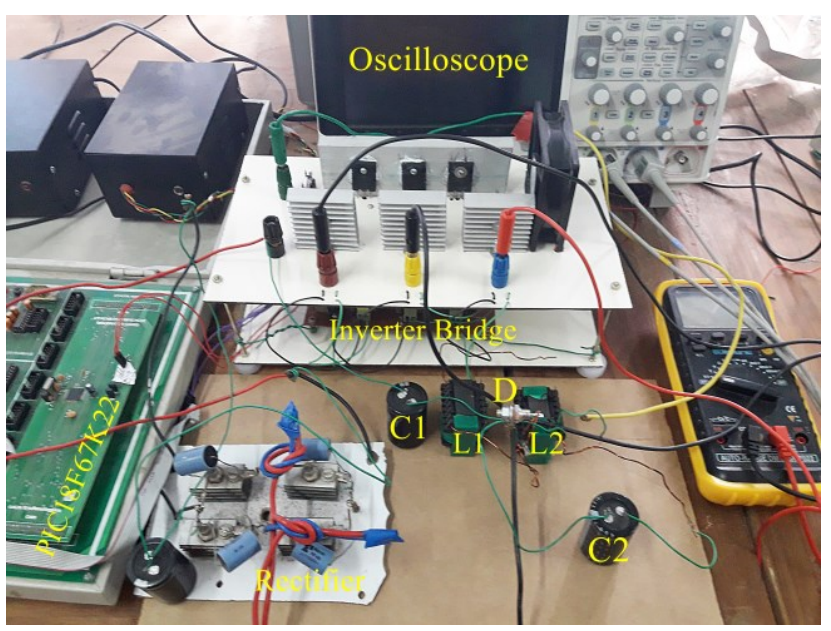

Fig. 9. Experimental set-up.

\section{CONCLUSIONS}

In this paper, Optimized HRPWM technique has been proposed for three-phase qZSI. The suggested concept is validated in both software and hardware platforms. The optimized performance between minimization of WTHD and maximization of voltage boosting capability has been achieved at various values of modulation index. In this context, the PSOGSA algorithm is used to obtain the optimum switching angles at different values of modulation index. The obtained optimum WTHDs up to $49^{\text {th }}$ order harmonics, boosting factors and sets of switching angles are presented in the result section of this paper. It can be concluded from various obtained results that the proposed PWM approach is useful for medium or high power qZSI to get superior performances in comparison with $\mathrm{MBC}$ technique at low switching frequency operation.

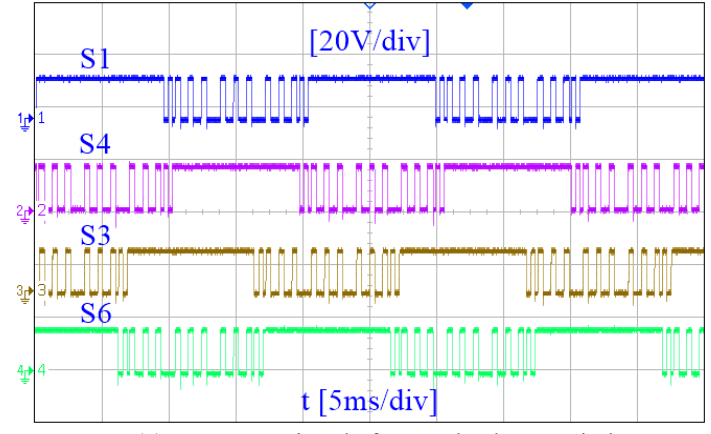

(a) HRPWM signals for a \& b-phase switches

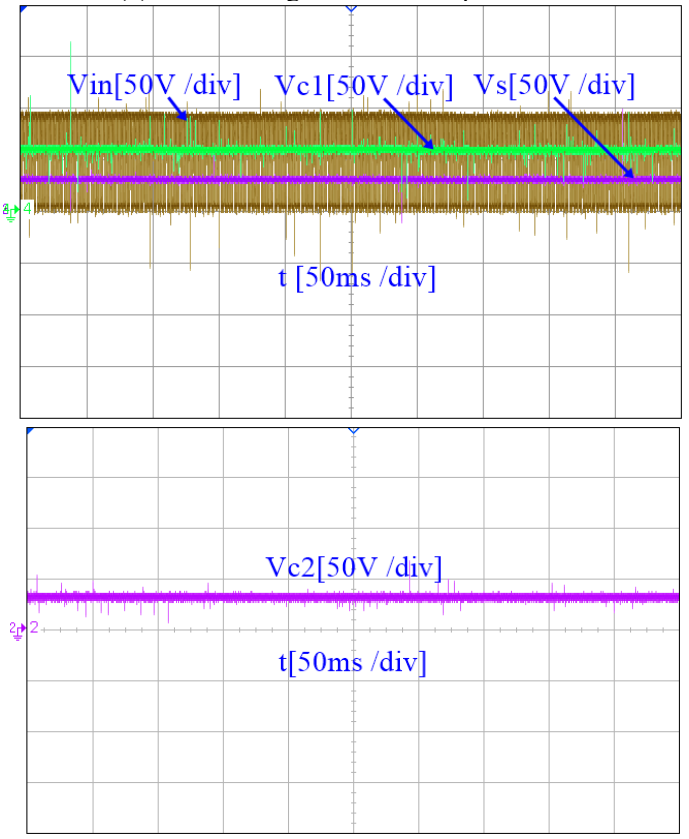

(b) Input, DC link, $\mathrm{C}_{1}$ and
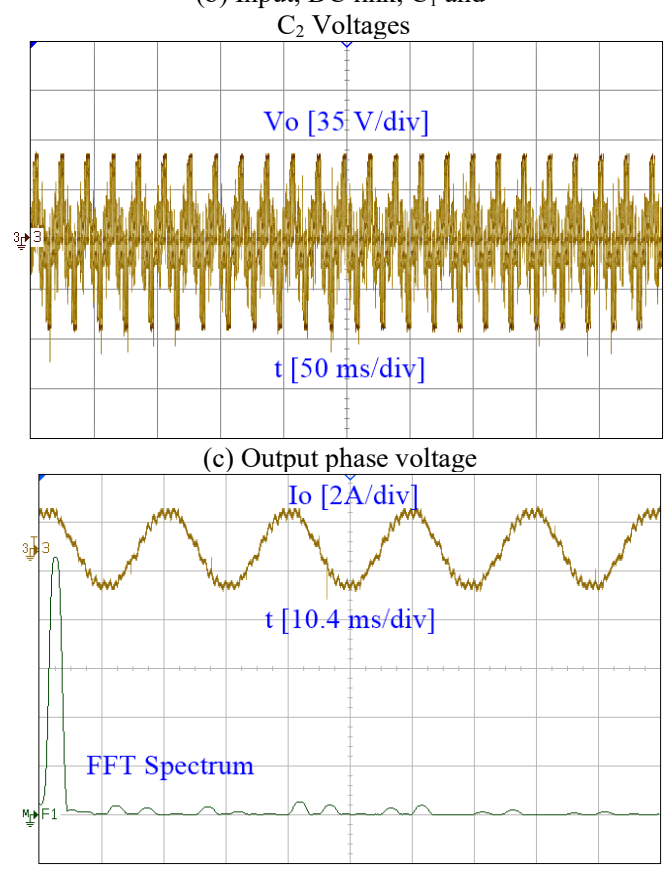

(d) Output phase current

Fig. 10. Various responses in hardware platform at $\mathrm{M}=0.8 \mathrm{pu}$.

\section{REFERENCES}

[1] A. Ayad, and R.Kennel, "A comparison of quasi-Z-source inverters and conventional two-stage inverters for PV applications, "EPE 
Journal, European Power Electronics and Drives, Vol. 27, no. 2, pp. 43-56, May 2017.

[2] Y.P.Siwakoti, F.Z.Peng, F.Blaabjerg, P.C.Loh, and G.E.Town, "Impedance-source networks for electric power conversion part I: A topological review," IEEE Trans. Power Electron., vol. 30, no. 2,pp. 699-716, Feb. 2015

[3] B. Ge, H. Abu-Rub, F. Z. Peng, Q. Li, A. T. de Almeida, F. J. T. E. Ferreira, D. Sun, and Y. Liu, "An energy stored quasi-Z-source inverter for application to photovoltaic power system," IEEE Trans. Ind. Electron., vol. 60, no. 10, pp. 4468-4481, Oct. 2013.

[4] O. Ellabban and H. Abu-Rub, "Z-source inverter: Topology improvements review," IEEE Ind. Electron. Mag., vol. 10, no. 1, pp. 6-24, Mar. 2016.

[5] F. Z. Peng, "Z-source inverter," IEEE Trans. Ind. Appl., vol. 39, no. 2, pp. 504-510, Mar./Apr. 2003.

[6] C. J. Gajanayake, D. M. Vilathgamuwa, P. C. Loh, R. Teodorescu, and F. Blaabjerg, "Z-source-inverter-based flexible distributed generation system solution for grid power quality improvement," IEEE Trans. Energy Convers., vol. 24, no. 3, pp. 695-704, Sep. 2009.

[7] Y. Li, J. Anderson, F. Z. Peng, and D. Liu, "Quasi-Z-source inverter for photovoltaic power generation systems," in Proc. 24th Annual IEEE APEC, Feb. 15-19, 2009, pp. 918-924.

[8] Y. Li, S. Jiang, J. G. Cintron-Rivera, and F. Z. Peng, "Modeling and control of quasi-Z-source inverter for distributed generation applications," IEEE Trans. Ind. Electron., vol. 60, no. 4, pp. 15321541, Apr. 2013.

[9] Y. P. Siwakoti, F. Z. Peng, F. Blaabjerg, P. C. Loh, G. E. Town, and S. Yang "Impedance Source Networks for Electric Power Conversion Part II: Review of Control and Modulation Techniques," IEEE Trans. Power Electron, vol. 30, no. 4, pp. 1887-1906, Apr. 2015.

[10] A. Abdelhakim, F. Blaabjerg, and P. Mattavelli, "Modulation schemes of the three-phase impedance source inverters-Part I: Classification and review," IEEE Trans. Ind. Electron., vol. 65, no. 8, pp. 63096320,Aug. 2018.

[11] F. Z. Peng, M. Shen, and Z. Qian, "Maximum boost control of the Zsource inverter," IEEE Trans. Power Electron., vol. 20, no. 4, pp. 833838, Jul. 2005.

[12] Q. Lei, D. Cao, and F. Z. Peng, "Novel loss and harmonic minimized vector modulation for a current-fed quasi-Z-source inverter in HEV motor drive application," IEEE Trans. Power Electron., vol. 29, no. 3,pp. 1344-1357, Mar. 2014.

[13] A. Abdelhakim, P. Davari, F. Blaabjerg, and P. Mattavelli, "Switching loss reduction in the three-phase quasi-Z-source inverters utilizing modified space vector modulation strategies," IEEE Trans. Power Electron., vol. 33, no. 5, pp. 4045-4046, May 2018.

[14] M. Shen, J. Wang, A. Joseph, F. Z. Peng, L. M. Tolbert, and D. J Adams, "Maximum constant boost control of the Z-source inverter," in Proc. IEEE Annu. Ind. Appl. Conf., Oct. 2004, pp. 142-147.

[15] Y. Tang, S. Xie, and J. Ding, "Pulse width modulation of Z-source inverters with minimum inductor current ripple," IEEE Trans. Ind.Electron., vol. 61, no. 1, pp. 98-106, Jan. 2014.

[16] S. Yang, X. Ding, F. Zhang, F. Z. Peng, and Z. Qian, "Unified control technique for Z-source inverter," in Proc. IEEE Power Electron. Spec. Conf., Jun. 2008, pp. 3236-3242.

[17] Y. Liu, B. Ge, H. A. Rub, "Theoretical and Experimental Evaluation of Four Space-Vector Modulations Applied to Quasi-Z-Source Inverters," IET Power Electron., vol. 6, no. 7, pp. 1257-1269, 2013.

[18] Y. Liu, B. Ge, H. Abu-Rub, and F. Z. Peng, "Overview of space vector modulations for three-phase Z-source/quasi-Z-source invert-ers," IEEE Trans. Power Electron., vol. 29, no. 4, pp. 2098-2108, Apr. 2014.

[19] Y. He, Y. Xu, and J. Chen, "New space vector modulation strategies to reduce inductor current ripple of Z-source inverter," IEEE Trans. Power Electron., vol. 33, no. 3, pp. 2643-2654, Mar. 2018.

[20] S. Nassereddine, S. Mekhilef, and A. Masaoud, "A simplified timedomain modulation scheme-based maximum boost control for threephase quasi-Z source inverters," IEEE J. Emerg. Sel. Topics Power Electron., vol. 6, no. 2, pp. 760-769, Jun. 2018.

[21] N. Sabeur, S. Mekhilef, A. Masaoud, "Extended maximum boost control scheme based on single-phase modulator for three-phase Z- source inverter," IET Power Electron., vol. 9, no.4, pp. 669-679, 2016.

[22] Y. Zhang, J. Liu, X. Li, X. Ma, S. Zhou, H. Wang, and Y. Liu, "An improved pwm strategy for $z$-source inverter with maximum boost capability and minimum switching frequency," IEEE Trans. on Power Electron., vol. PP, no. 99, pp. 606-628, 2017.

[23] Y. Zhou, Q. Wu, Z. Li, and F. Hong, "Research on a Time-variant Shoot-through Modulation Strategy for Quasi-Z-source Inverter," IEEE Trans. on Power Electron., vol. 33, no. 11, pp. 9104-9109, Nov. 2018.

[24] P. Liu, J. Xu, Y. Yang, H. Wang and F. Blaabjerg, "Impact of modulation strategies on the reliability and harmonics of impedance-source inverters," in IEEE Journal of Emerging and Selected Topics in Power Electron., Early Access, pp. 1-1.

[25] A. Abdelhakim, F. Blaabjerg, and P. Mattavelli, "Modulation schemes of the three-phase impedance source inverters-Part II: Comparative assessment," IEEE Trans. Ind. Electron., vol. 65, no. 8, pp. 63216332,Aug. 2018.

[26] R. Salehi, N. Farokhnia, M. Abedi, and S. H. Fathi, "Elimination of low order harmonics in multilevel inverters using genetic algorithm," J. Power Electron., Vol. 11, No.2 pp. 132-139, Mar. 2011.

[27] Y. Chen, X. Guo, J. Xue, and Y. Chen, "Hybrid PWM Modulation Technology Applied to Three-Level Topology-Based PMSMs," $J$. Power Electron., Vol. 19, No. 1, pp. 146-157, Jan. 2019.

[28] S. Mirjalili, S.Z.M.Hashim, "A new hybrid PSOGSA algorithm for function optimization," in Int. Conf. on Computer and Information Application (ICCIA 2010), 2010, pp. 374-377.

[29] J. Chiasson, L. M. Tolbert, K. McKenzie, and Z. Du, "A complete solution to the harmonic elimination problem," IEEE Trans. Power Electron., vol. 19, no. 2, pp. 491-499, Mar. 2004.

[30] S. Ganguly, A. Sadhukhan, P. K. Gayen and S. Dolui, "Hardware implementation of single-phase full-bridge VSI switched by PSO based SHEPWM signals using embedded PIC microcontroller," 2017 IEEE Calcutta Conference (CALCON), Kolkata, 2017, pp. 341-346. doi: 10.1109/CALCON.2017.8280752.

[31] C.K. Duffey, R.P. Stratford, "Update of harmonic standard IEEE-519: IEEE recommended practices and requirements for harmonic control in electric power systems," IEEE Trans. Ind. Appl., vol. 25, no. 6, pp. 1025-1034, Nov./Dec. 1989. 